\title{
EDUCAÇÃO INCLUSIVA: UM ESTUDO NA ÁREA DA EDUCAÇÃO FÍSICA
}

\author{
INCLUSIVE EDUCATION: A STUDY IN THE PHYSICAL EDUCATION FIELD \\ João Serapião de AGUIAR ${ }^{1}$ \\ Édison DUARTE ${ }^{2}$
}

\begin{abstract}
RESUMO: o presente estudo teve por objetivo investigar os significados da inclusão de pessoas com necessidades especiais nas aulas de educação física no sistema regular de ensino. A amostra foi constituída de 67 participantes, assistentes técnicos pedagógicos de Educação Física de Diretorias de Ensino do Estado de São Paulo. Trinta informantes eram do sexo masculino, 57 cursaram faculdades privadas e 10 públicas, 29 possuíam curso de especialização, 57 tinham mais de 10 anos de experiência na área da Educação Física Escolar, 5 tinham entre 5 e 10 anos de experiência e 5 entre 1 e 5 anos, a idade entre eles variou de 27 a 58 anos. Para coleta de dados foi utilizado como instrumento um questionário do tipo semi-estruturado, composto por 10 questões fechadas e 4 abertas. Os resultados apontaram que cerca de $97 \%$ dos participantes não possuíam conhecimentos suficientes para incluir alunos portadores de necessidades especiais nas aulas de Educação Física e que também, por volta de $97 \%$, acreditavam que a participação do aluno portador de deficiência em aulas de Educação Física pode auxiliar na sua inclusão na comunidade escolar. Os resultados também indicaram que para realizar a inclusão os professores necessitam de: a) apoio do governo, no que se refere a oferecimento de cursos de reciclagem; b) auxílio técnico pedagógico especializado; c) estrutura adaptada do espaço físico; e d) material didático adequado.
\end{abstract}

PALAVRAS-CHAVE: educação inclusiva; educação física; formação do professor de educação física; pessoas com necessidades especiais; ensino regular.

ABSTRACT: the present study aimed to investigate the meaning of the inclusion of people with special needs in the Physical Education classes of the regular teaching system. The sample had 67 participants, technical pedagogical assistants of Physical Education of the Education Board Districts of the State of São Paulo. Thirty participants were male, 57 studied in private colleges and 10 in public colleges, 29 had specialization course, 57 had more than 10 years of experience in the area of physical education, 5 had between 5 and 10 years of experience and 5 between 1 to 5 years, ages varying from 27 to 58 . A semi-structured questionnaire, composed of 10 closed questions and 4 open questions, was used for data collecting. The results pointed out that about 97\% of the participants did not have enough knowledge to include bearers of special needs in the Physical Education classes and that about $97 \%$ believed that the participation of a student with deficiency in the Physical Education classes would help the inclusion of that pupil in the school community. The results also indicated that to carry out inclusion, teachers would need: a) government support to offer training courses; b) specialized technical pedagogical support; c) structure adapted to the physical space; and d) adequate didactical material.

KEYWORDS: inclusive education, physical education; preparation of the physical education teacher; people with special needs; regular teaching.

\section{INTRODUÇÃO}

\section{EducaÇão InClusiva, ASPECTOS Da FormaÇÃo do PROFISSIONAL de EdUCAÇão Física E EXPECTATIVAS ATUAIS DA PRÁTICA PEDAGÓGICA DESSE DOCENTE NA EDUCAÇÃO BÁSICA.}

Para Sassaki (1997), a inclusão social vem acontecendo e se efetivando em países desenvolvidos desde a década de 80. De acordo com Aguiar (2002; 2004), no Brasil foi só a partir da Constituição da República Federativa de 1988 que aumentou o número de estudos voltados para essa área. Ainda segundo Aguiar, no campo da educação formal eles começaram a ocorrer, de forma mais sistemática, após a Lei de Diretrizes e Bases da Educação Nacional, de 20 de dezembro de 1996.

${ }^{1}$ Prof. das Faculdades de Educação Física e Psicologia da PUC-Campinas - serapio@bol.com.br

${ }^{2}$ Prof. da Faculdade de Educação Física da Unicamp. 
De acordo com Carvalho (1998) e Oliveira e Poker (2002), o paradigma da escola inclusiva pressupõe, conceitualmente, uma educação apropriada e de qualidade dada conjuntamente para todos os alunos - considerados dentro dos padrões da normalidade com os com necessidades educacionais especiais - nas classes do ensino comum, da escola regular, onde deve ser desenvolvido um trabalho pedagógico que sirva a todos os alunos, indiscriminadamente. Sendo assim, o ensino inclusivo é a prática da inclusão de todos, independente de seu talento, deficiência (sensorial, física ou cognitiva), origem sócio-econômica, étnica ou cultural.

Para Cardoso (2003) a inclusão de alunos com necessidades especiais na escola regular, constitui uma perspectiva e um desafio para o século XXI, cada vez mais firme, nos diferentes sistemas e níveis educativos.

No que se refere, especificamente, às pessoas com necessidades especiais e aos cursos de Educação Física, assunto ligado a este estudo, Cidade e Freitas (2002) afirmam que:

No que concerne à área da Educação Física, a Educação Física Adaptada surgiu oficialmente nos cursos de graduação, por meio da Resolução número 03/87, do Conselho Federal de Educação, que prevê a atuação do professor de Educação Física com o portador de deficiência e outras necessidades especiais. A nosso ver, esta é uma das razões pelas quais muitos professores de Educação Física, hoje atuando nas escolas, não receberam em sua formação conteúdos e/ou assuntos pertinentes à Educação Física Adaptada ou à inclusão (p. 27).

Duarte (2003), diz que, somente a partir da última década, os cursos de Educação Física colocaram em seus programas curriculares, conteúdos relativos às pessoas com necessidades especiais e que o material didático que trata das formas de trabalho com essa população, escrito em nossa língua, é escasso.

Para ilustrar a posição de Duarte, pode-se citar, como exemplo, a Faculdade de Educação Física da PUC-Campinas, que, para atender à Resolução Federal $n^{\circ} 3 / 87$, reformulou o seu currículo, implantando-o no ano de 1990. Esse currículo oferecia o curso em 4 anos e na sua grade a disciplina Educação Física Adaptada aparecia na última série. Portanto, nessa Faculdade, esse componente curricular só foi oferecido em 1993.

Ainda que de maneira ampla, Inclusão, Parâmetros Curriculares Nacionais e Educação Física têm suas discussões colocadas na ordem do dia no contexto educacional atual.

O autor deste projeto de pesquisa acredita que a Educação Física, como um dos componentes curriculares da educação básica, não pode ficar indiferente ou neutra face ao movimento da educação inclusiva. Como faz parte integrante do currículo oferecido pela escola, essa disciplina deve-se constituir num dos adjuvantes do processo da inclusão escolar e social. Para tanto, há necessidade que os cursos de educação superior, que formam o licenciado em Educação Física, desenvolvam competências para esse fim. 
Culturalmente, a formação pedagógica do professor de Educação Física vem sendo colocada em plano secundário, prevalecendo os conteúdos das disciplinas de cunho técnico- desportivo, corporal e biológico, em detrimento das disciplinas pedagógicas (SILVA, 1993). Sendo assim, a formação vem privilegiando o desenvolvimento de capacidades e habilidades físicas, que tem por prioridade o desempenho físico, técnico e o corpo enquanto objeto de consumo.

Com base nessa visão, a cultura desportiva e competitiva, historicamente dominante nas propostas curriculares da Educação Física, pode criar resistências à inclusão de pessoas que são encaradas como menos capazes para um bom desempenho numa competição. Muitas das proposições de atividades feitas em Educação Física, realizadas na base da cultura competitiva, podem ser observadas nas escolas. A prática desportiva, quando usada sem os princípios da inclusão, é uma atividade que não favorece a cooperação, que não valoriza a diversidade e que pode gerar sentimentos de satisfação e de frustração. Essa cultura competitiva constitui uma fonte de exclusão e pode se consistir numa barreira à educação inclusiva. É bom salientar que, na rede de ensino, a Educação Física é a única disciplina que tem legislação específica para que certos alunos sejam dispensados de suas aulas, sendo que, determinados perfis biológicos de desempenhos motores podem ser uma das normas dessa dispensa. Como exemplo de legislação específica dessa área pode-se citar a Resolução $n^{\circ} 11$, de 18 de janeiro de 1980, da Secretaria de Estado da Educação, do Estado de São Paulo, ainda em vigor, que dispõe sobre aulas de Educação Física nos estabelecimentos da rede estadual de ensino.

Com princípios educacionais contrários à formação histórica supracitada, os Parâmetros Curriculares Nacionais para o Ensino Fundamental (BRASIL, Ministério da Educação e do Desporto, 1998), espera que, na prática pedagógica, os professores tenham uma ação diferente dessa formação. Recomendam que "as políticas educacionais devem ser suficientemente diversificadas e concebidas, de modo a que a educação não seja um fator suplementar da exclusão social" (p. 17).

Esses Parâmetros (p. 55) indicam, em seus objetivos, que os alunos do ensino fundamental devem ser capazes de:

- compreender a cidadania como participação social e política, assim como exercício de direitos e deveres políticos, civis e sociais, adotando no dia-a-dia, atitudes de solidariedade, cooperação e repúdio às injustiças, respeitando o outro e exigindo para si o mesmo respeito;

. conhecer e valorizar a pluralidade do patrimônio sociocultural brasileiro, bem como aspectos socioculturais de outros povos e nações, posicionando-se contra qualquer discriminação baseada em diferenças culturais, de classe social, de crenças, de sexo, de etnia ou outras características individuais e sociais.

Com base nos mesmos princípios teóricos educacionais, os Parâmetros Curriculares Nacionais de Educação Física para o Ensino Fundamental (BRASIL, Ministério da Educação e do Desporto, 1997) expressam, em seus objetivos gerais, a expectativa que os alunos sejam capazes de: 
- participar de atividades corporais, estabelecendo relações equilibradas e construtivas com os outros, reconhecendo e respeitando características físicas e de desempenho de si próprio e dos outros, sem discriminar por características pessoais, físicas, sexuais ou sociais (p. 43);

- participar de diferentes atividades corporais, procurando adotar uma atitude cooperativa e solidária, sem discriminar os colegas pelo desempenho ou por razões sociais, físicas, sexuais ou culturais (p. 63);

- participar de atividades corporais, reconhecendo e respeitando algumas de suas características físicas e de desempenho motor, bem como as de seus colegas, sem discriminar por características pessoais, físicas, sexuais ou sociais (p. 71);

- conhecer, valorizar, apreciar e desfrutar de algumas das diferentes manifestações de cultura corpórea, adotando uma postura não-preconceituosa ou discriminatória por razões sociais, sexuais ou culturais (p. 72).

Na mesma direção, os Parâmetros Curriculares Nacionais para o Ensino Médio (BRASIL, Ministério da Educação e do Desporto, 1999) no que se refere aos conhecimentos de Educação Física, apontam que o esporte de cunho educativo deve ser trabalhado na escola e que a prática do mesmo deve atender a todos os alunos, respeitando suas diferenças e estimulando-os ao maior conhecimento de si e de suas potencialidades. Esses Parâmetros realçam que o significado do trabalho em grupo está em valorizar a interação aluno-aluno e professor-aluno como fonte de desenvolvimento social, pessoal e intelectual; e frisam que situações de grupo exigem dos alunos a consideração das diferenças individuais e de respeito aos outros, num exercício de ética e cidadania.

Os Parâmetros Curriculares Nacionais para o Ensino Fundamental (BRASIL, Ministério da Educação e do Desporto, 1998, p. 62), no que se refere a contribuição das diferentes áreas de conhecimento, apontam em relação à Educação Física:

[...] é a área do conhecimento que introduz e integra os alunos na cultura corporal do movimento, com finalidades de lazer, de expressão de sentimentos, afetos e emoções, de manutenção e melhoria da saúde.

Para tanto, deve romper com o tratamento tradicional dos conteúdos que favorece os alunos que já têm aptidões, adotando como eixo estrutural da ação pedagógica o princípio da inclusão, apontando para uma perspectiva metodológica de ensino e aprendizagem que busca o desenvolvimento da autonomia, da cooperação, da participação social e da afirmação de valores e princípios democráticos. Nesse sentido, deve buscar garantir a todos a possibilidade de usufruir de jogos, esportes, danças, lutas e ginástica em benefício do exercício crítico da cidadania.

Souza (2003), num estudo que realizou com 5 participantes (professores de educação física) sobre o tema inclusão do educando com deficiência no ensino regular da escola pública, diz que a inclusão implica em gestão democrática na escola e que, numa sociedade que gera e administra uma legião de excluídos, com prioridades sociais competitivas, discutir inclusão torna-se tarefa bastante embaraçosa e difícil. 
A presença do deficiente na escola pressupõe uma mudança radical no interior da mesma, seja nos procedimentos de ensino, na avaliação, no currículo, enfim, em todas as áreas do sistema escolar.

Pode-se mesmo dizer, que há múltiplos aspectos a serem considerados para a implementação de uma escola inclusiva. Dentre esses estão o oferecimento de cursos de reciclagem para capacitação de docentes; a importância da existência de um corpo técnico especializado (composto por psicólogo, fonoaudiólogo e psicopedagogo); o apoio da família do aluno com necessidades especiais; o número de alunos na classe; a eliminação de barreiras arquitetônicas; a revisão pela sociedade civil da concepção sobre a pessoa com necessidades especiais; o apoio da sociedade política; a destinação de verbas; a adequação de currículos, metodologias de ensino, recursos didáticos e materiais e sistemas de avaliação (ARANHA, 2000; BERALDO, 1999; BUENO; RESA, 1995, CARDOSO, 1992; DAMIÃO, 2000; JANNUZZI, 1993; LÜSCHER, 1999; MACHADO, SOUSA, SAYÃO, 1997; MANTOAN 1989, 1997, 1998, 2003; MARTINS, 1996; MAZZOTA, 1993, 1994; MENDES, 1999, 2000; MRECH, 1999; SANTOS, 1992; SASSAKI, 1999; STAINBACK; STAINBACK , 1999).

Na área de procedimentos de ensino, Aguiar (2002) elaborou um estudo que teve por objetivos averiguar a influência do jogo sobre a aprendizagem de conceitos básicos à leitura e à escrita em deficientes mentais alfabetizáveis e verificar a sua generalização para situações do contexto escolar. A amostra foi constituída de 15 participantes, onze meninos e quatro meninas, de oito a treze anos de idade, de famílias de renda baixa. O ensino de conceitos foi baseado em uma concepção que tem por base o princípio da interligação entre a ação e o desenvolvimento cognitivo, e o jogo com forma de ensino, mediado pela linguagem oral, por objetos e figuras. Utilizou-se, também, estratégias para a ocorrência do aprendizado cooperativo, com criações de situações desafiadoras visando acionar os esquemas cognitivos dos participantes. Os resultados apontaram efeitos positivos dos procedimentos utilizados, com implicações para a educação inclusiva.

Na área da avaliação, Fávero, Pantoja e Mantoan (2004), no manual que apresentam sobre educação inclusiva, indicam como adequada a avaliação do tipo processual. Essa avaliação proposta pressupõe diagnóstico e acompanhamento individual do percurso de cada estudante, do ponto de vista da sua evolução, de suas competências, habilidades, conhecimentos e atitudes. É de caráter não classificatório, dinâmica e contínua, e deve mapear o processo de aprendizagem de cada aluno, respeitando os avanços, retrocessos, dificuldades e progressos individuais. Sendo dessa forma, o sucesso da aprendizagem está em explorar talentos, atualizar possibilidades e desenvolver predisposições naturais de cada aluno. As dificuldades, deficiências e limitações de cada discente devem ser reconhecidas, porém, não devem conduzir ou restringir o processo de ensino. Este deve se desenvolver com base numa pedagogia ativa, dialógica e interativa. Nesse processo, as estratégias de ensino devem envolver ação cooperativa, desafios cognitivos e auto-avaliação. Fávero, Pantoja e Mantoan (2004) propõem no manual um sistema de aprovação estruturada por ciclos de formação e desenvolvimento. 
Com o princípio da Inclusão, a Educação Física escolar deve ter como eixo fundamental o aluno e, sendo assim, deve desenvolver as competências de todos os discentes e dar aos mesmos condições para que tenham acesso aos conteúdos que propõe, com participação plena, adotando para tanto estratégias adequadas, evitando a exclusão ou alienação.

Assim, a concepção de cultura corporal do movimento, esposada pelos Parâmetros Curriculares Nacionais, amplia a contribuição da Educação Física escolar para o pleno exercício da cidadania, modificando, dessa forma, a história desse componente curricular que, pela formação acadêmica do professor dessa disciplina, vem apontando para um processo de ensino e aprendizagem centrado no desenvolvimento de capacidades e habilidades físicas, que objetiva e privilegia o desempenho físico e técnico, o qual, quase sempre, resulta numa constante seleção entre pessoas aptas e inaptas para a prática da cultura corporal do movimento.

Beraldo (1999) realizou um estudo a respeito das percepções dos professores da escola pública sobre a inserção do aluno tido como deficiente mental em classes regulares de ensino. Essa pesquisa teve por objetivos: 1. verificar as percepções que professores da rede oficial do ensino estadual têm sobre a inclusão de alunos tidos como deficientes mentais em suas salas de aula no ensino regular; 2. identificar, a partir da própria vivência do docente, sugestões para enfrentar as dificuldades surgidas no processo de inclusão; e 3. descrever as ações concretas que o professor já vem executando para favorecer a inclusão. Participaram do estudo 10 professoras do ensino regular que tinham em sua sala de aula alunos tidos como deficientes mentais. Essas docentes pertenciam a seis escolas da rede oficial do ensino estadual, localizadas em cinco municípios do interior do estado de São Paulo. A pesquisa foi exploratória e os dados foram coletados através de entrevistas semi-estruturadas. A análise, de cunho qualitativo, foi feita à base das falas das professoras. Na perspectiva das professoras, o professor necessita de: a-) apoio do governo, no que se refere a oferecimento de cursos de reciclagem (tiveram uma formação voltada para a prática pedagógica apenas para pessoas tidas como normais); b-) de um corpo técnico especializado (composto por psicólogo, fonoaudiólogo e psicopedagogo); e c-) apoio da família do aluno tido como deficiente mental. Diz também a referida autora que o processo de inclusão necessita de intervenções estruturais essenciais, profundas e urgentes, que vão desde a adequada capacitação dos docentes, até questões estruturais administrativas, como número de alunos em classe, eliminação de barreiras arquitetônicas, recursos materiais adequados para o ensino e adaptações pedagógicas para o deficiente.

As perspectivas das professoras apresentadas na pesquisa de Beraldo (1999) para implantação da educação inclusiva, no que se refere a mudanças radicais no interior da escola, no tocante ao currículo, sistema de avaliação e presença de um corpo técnico especializado (composto por psicólogo, fonoaudiólogo e psicopedagogo), foram coincidentes as apresentadas em depoimentos dos participantes do estudo de Souza (2003). 
Num questionamento sobre a educação inclusiva, Mendes (1999) diz que a mesma é hoje um grande desafio para o país e que a análise, na perspectiva empírica, permite constatar que:

\begin{abstract}
...a inclusão total (se entendida como a inserção de todas as crianças e jovens, independente do tipo e grau de limitação, na classe regular, por tempo integral e sem qualquer outro tipo de apoio) é uma resposta muito simplista e equivocada a um tema demasiadamente complexo, e que, se caracteriza no momento por uma confiança excessiva na retórica e pela falta de evidências científicas. É muito mais uma questão de crença, ou religião do que de ciência (p.18).
\end{abstract}

Carmo (2002), ao escrever um texto sobre inclusão escolar e a Educação Física, diz que seu objetivo em escrevê-lo foi muito mais de conclamar os pesquisadores da área para solucionar o desafio da inclusão, do que para apresentar propostas e soluções. Termina sua redação dizendo que atualmente possui muito mais dúvidas do que respostas e que espera que as dúvidas sejam o motor propulsor de reflexões à busca de alternativas superadoras.

Pelas várias colocações feitas, pode-se perceber que múltiplos aspectos têm sido levantados e estudados no campo da implementação efetiva da educação inclusiva, este estudo realizado na área da Educação Física teve por objetivos:

1. Geral

- Investigar os significados da inclusão de pessoas com necessidades especiais nas aulas de educação física no ensino regular.

2. Específicos

- identificar conhecimentos dos professores de educação física sobre educação inclusiva e educação especial e/ou educação física adaptada.

- investigar o conhecimento dos professores de educação física, sobre inclusão da pessoa com deficiência nas aulas de educação física da rede de ensino regular.

- averiguar aspectos facilitadores e entraves para a atuação do professor de educação física que tenha em suas aulas alunos com deficiências.

- verificar, na opinião dos professores de educação física, se a inclusão da pessoa com deficiência em aulas de educação física pode auxiliar no processo da inclusão escolar.

\title{
Método
}

INFORMANTES

Participaram deste estudo, compondo a amostra, 67 assistentes técnicos pedagógicos de Educação Física de Diretorias de Ensino do Estado de São Paulo. Trinta eram do sexo masculino, 57 cursaram faculdades privadas e 10 públicas, 29 possuíam curso de especialização, 57 tinham mais de 10 anos de experiência na área da Educação Física Escolar, 5 tinham entre 5 e 10 anos de experiência e 5 entre 1 e 5 anos, a idade entre eles variou de 27 a 58 anos. 
Os assistentes técnicos pedagógicos de Diretorias de Ensino são professores de uma determinada disciplina, que têm como uma de suas principais funções divulgar para os seus pares assuntos pertinentes aos componentes curriculares a que pertencem, inclusive, como docentes multiplicadores, montando e oferecendo cursos específicos da área. É bom frisar que as Diretorias de Ensino têm um assistente técnico pedagógico por disciplina, que se responsabiliza por ações junto a professores de escolas que estão sob a jurisdição da Diretoria a que pertencem.

\section{Material}

Para coleta de dados foi utilizado, como instrumento, um questionário do tipo semi-estruturado, composto por 10 questões fechadas e 4 abertas. Esse questionário foi o seguinte:

\section{QuestionÁRIO}

Este questionário faz parte de uma pesquisa que está sendo realizada com professores de Educação Física, para discutir algumas idéias relevantes para a área. Não há necessidade de identificar-se. A sua participação é de grande importância.

Observ.: caso o espaço seja insuficiente utilize o verso.

\begin{tabular}{|l|l|}
\hline $\begin{array}{l}\text { 1) Faculdade de origem } \\
\text { ( ) pública } \\
\text { ( ) privada }\end{array}$ & $\begin{array}{l}\text { 8) Possui algum aluno Portador de } \\
\text { Deficiência na sua escola? } \\
\text { ( ) sim } \\
\text { ( ) não }\end{array}$ \\
\hline $\begin{array}{l}\text { 2) Sexo } \\
\text { ( ) masculino } \\
\text { ( ) feminino anos } \\
\text { Idade: }\end{array}$ & $\begin{array}{l}\text { 9) Em caso afirmativo que tipo de } \\
\text { deficiência? } \\
\text { ( ) física } \\
\text { ( ) mental } \\
\text { ( ) auditiva }\end{array}$ \\
( ) visual \\
( ) outras
\end{tabular}




\begin{tabular}{|l|l|}
\hline 1) Caso possua, onde obteve essas informações? & 13) Na sua opinião, a participação do aluno \\
portador de deficiência em aulas de Educação \\
( ) curso de graduação & Física auxilia a inclusão do aluno na \\
comunidade escolar? & ( ) sim \\
( ) palestras & ( ) não \\
$\begin{array}{l}\text { ( ) mestrado de especialização } \\
\text { ( ) doutorado }\end{array}$ & \\
$\begin{array}{l}\text { ( ) leituras independentes } \\
\text { ( ) outros }\end{array}$ & \\
\hline $\begin{array}{l}\text { O que você entende por inclusão de Pessoas } \\
\text { Portadoras de Deficiência no ensino regular? }\end{array}$ & 14) Em caso afirmativo, por quê e de que \\
\hline
\end{tabular}

\section{Procedimentos}

A aplicação do instrumento ocorreu em 2004, por ocasião da realização de um curso de capacitação em Educação Física Adaptada para Assistentes Técnicos Pedagógicos, professores de Educação Física. Esse curso foi organizado pelo Centro de Apoio Pedagógico Especializado da Secretária de Estado da Educação de São Paulo.

O primeiro passo para a aplicação do questionário foi o de solicitar autorização aos organizadores do curso, explicando aos mesmos os objetivos da pesquisa e a ética que envolve estudos desse tipo. Com a anuência dos organizadores deu-se a aplicação do questionário. Foi entregue um para cada assistente técnico pedagógico responder, na própria sala onde ocorriam as palestras do curso, sendo que foi solicitado a todos os informantes que quiseram participar do estudo, após terem tido esclarecimentos sobre o mesmo, que assinassem um Termo de Consentimento para Participação em Pesquisa (em anexo), segundo a orientação da Resolução no 196/96 do Ministério da Saúde, a respeito de pesquisas envolvendo seres humanos. Antes de se aplicar o instrumento foi feito o pré-teste do mesmo, para verificar sua fidedignidade, validade e operatividade. Aferiu-se o questionário aplicando-o em nove professores de Educação Física que, na ocasião, realizavam curso de pós-graduação, em uma Universidade do interior do estado de São Paulo.

\section{Resultados E Discussão}

O estudo estatístico feito foi descritivo e qualitativo (não-paramétrico), tendo em vista que na pesquisa não houve nenhuma manipulação para a seleção da amostra de informantes e, também, não houve grupo de controle.

A análise das respostas foi realizada visando-se a consecução dos objetivos do estudo, sendo feita uma análise quantitativa e qualitativa das respostas obtidas. A análise das respostas às questões fechadas consistiu na interpretação das estatísticas descritivas, de forma que se pudesse obter uma visão de como os 
dados estavam distribuídos e como se diferenciavam por questões. Para a análise das respostas às questões abertas, passíveis de quantificação percentual, foi elaborada essa quantificação. Para analisar as respostas discursivas às questões abertas, não passíveis de quantificação, foram destacados períodos, marcas discursivas relevantes aos objetivos do estudo.

Na Tabela 1 pode-se ver que cerca de $85,1 \%$ dos informantes formaramse em faculdades privadas e, aproximadamente, 14,9\% em públicas. Na Tabela 2 pode-se observar que por volta de $56,7 \%$ dos participantes tinham apenas curso de graduação em Educação Física e que cerca de 43,3\% tinham curso de graduação e especialização na área.

Tabela 1 - Faculdade de Origem.

\begin{tabular}{lll}
\hline origem & $\mathrm{n}$ & $\%$ \\
\hline pública & 10 & $14,9 \%$ \\
privada & 57 & $85,1 \%$ \\
total & 67 & $100,0 \%$ \\
\hline
\end{tabular}

Tabela 2 - Formação Acadêmica.

\begin{tabular}{lll}
\hline Form ação acadêm ica & $\mathrm{N}$ & $\%$ \\
\hline A penas Graduação & 38 & $56,7 \%$ \\
Graduação e Especialização & 29 & $43,3 \%$ \\
total & 67 & $100,0 \%$ \\
\hline
\end{tabular}

Observando a Tabela 3, vê-se que 57 dos participantes, cerca de 85,0\%, tinham mais de 10 anos de tempo de atuação na área da Educação Física Escolar, 5 dos informantes, que corresponde aproximadamente a 7,5\%, tinham entre 1 a 5 anos de tempo de atuação e outros 5, entre 5 a 10 anos.

Tabela 3 - Tempo de atuação na área de Educação Física Escolar.

\begin{tabular}{ccc}
\hline Tempo de Atuaça & n & \% \\
\hline Menos que 01 ano & 0 & $0,0 \%$ \\
Entre 1 e 5 anos & 5 & $7,5 \%$ \\
Entre 5 e 10 anos & 5 & $7,5 \%$ \\
Mais de 10 anos & 57 & $85,0 \%$ \\
total & 67 & $100,0 \%$ \\
\hline
\end{tabular}

A Tabela 4 mostra que cerca de $82,1 \%$ dos assistentes técnicos pedagógicos (55 professores), que participaram da pesquisa, responderam ter conhecimentos sobre educação especial e/ou educação física adaptada e que aproximadamente 17,9\% (12 docentes) informaram que não tinham conhecimento sobre o assunto. 
Tabela 4 - Conhecimentos sobre Educação Especial e/ ou Educação Física Adaptada.

\begin{tabular}{ccc}
\hline C onhecimento & n & $\%$ \\
\hline T in am C on e cim ento & 55 & $82,1 \%$ \\
N ão tinh a C o n e cim e n to & 12 & $17,9 \%$ \\
total & 67 & $100,0 \%$ \\
\hline
\end{tabular}

A Tabela 5 aponta que os participantes que disseram ter conhecimentos sobre Educação Especial e/ou Educação Física Adaptada, os adquiriram nas seguintes fontes: 42 professores (cerca de 62,7\%) em palestras, 32 docentes (aproximadamente 47,8\%) em leituras independentes; 26 professores (por volta de 38,8\%) em outras fontes, 20 docentes (aproximadamente 29,9\%) em cursos de extensão, 9 professores (cerca de 13,4\%) no curso de graduação e 5 docentes (por volta de 7,5\%) em curso de especialização. É bom salientar que, nessa questão, os informantes puderam assinalar como resposta mais de uma alternativa.

Tabela 5 - Fontes de obtenção dos conhecimentos sobre Educação Especial.

\begin{tabular}{ccc}
\hline Fontes & $\mathrm{n}$ & $\%$ \\
\hline Graduação & 9 & $13,4 \%$ \\
Extensão & 20 & $29,9 \%$ \\
Especialização & 5 & $7,5 \%$ \\
Palestras & 42 & $62,7 \%$ \\
Leituras & 32 & $47,8 \%$ \\
Outras Fontes & 26 & $38,8 \%$ \\
\hline
\end{tabular}

Em relação à questão aberta 7- O que você entende por Inclusão de Pessoas Portadoras de Deficiência no ensino regular, 11 professores, cerca de 16,4\%, não responderam à questão e 36 participantes, por volta de 53,7\%, responderam sem apresentar nenhum dos princípios básicos que caracterizam o paradigma conceitual da Inclusão. Fato que nos leva dizer que 47 dos informantes, cerca de 70,1\%, não tinham domínios da concepção da Inclusão, talvez pelo motivo desse assunto ser novo no Brasil e estar só após a resolução do Conselho Nacional de Educação/Câmara de Educação Básica no 2, de 11 de setembro de 2001, sendo discutida de forma mais sistemática. Como já foi dito, a implantação da Inclusão de pessoas portadoras de necessidades especiais no ensino regular está se dando de forma lenta e gradual no país.

Nessa mesma questão, 20 professores, por volta de 29,1\%, responderam apresentando alguns conhecimentos básicos de Inclusão Escolar. Chamou-nos atenção as respostas discursivas emitidas por três participantes, são elas: $1^{\text {a } ~ “ ~} \ldots$ a adaptação do espaço escolar para receber essa pessoa. Respeito aos limites e diferenças por parte de todos. Apoio de um corpo técnico especializado", $2^{\mathrm{a}}$ “ $\ldots$ alunos com deficiência freqüentando a classe com os alunos que não têm deficiência, não em classes específicas para portadores de necessidades especiais. Métodos pedagógicos adaptados para atender a todos"; $3^{\text {a } ~ " ~ . . . ~ a ~ i n c l u s a ̃ o ~ n a ̃ o ~ e ́ ~ s o ́ ~ p o r ~ m a i s ~}$ 
um na sala de aula, e sim dar condições para que ele se sinta como membro da classe - fazendo parte ativamente, em termos de relacionamento e conhecimento com os demais que são considerados normais".

As colocações desses três informantes apontam alguns aspectos característicos e significativos da Inclusão Escolar, já levantados e analisados por vários autores, como por Cardoso (1992), Januzzi (1993), Mazzotta (1993), Martins (1996), Luscher (1999), Carvalho (1998), Oliveira e Poker (2002), Aguiar (2002), Mantoan (2004) e Fávero, Pandoja e Mantoan (2004).

Como se pode verificar na Tabela 6 , cerca de $71,6 \%$ dos professores informantes, 48 docentes disseram ter em suas escolas de origem alunos com necessidades especiais e aproximadamente 28,4\%, 19 participantes, disseram não ter.

Tabela 6 - Existência de aluno portador de deficiência em sua escola de origem.

\begin{tabular}{lcc}
\hline & n & \% \\
\hline Escolas com alunos com deficiência & 48 & $71,6 \%$ \\
Escolas com alunos sem deficiência & 19 & $28,4 \%$ \\
Total & 67 & $100,0 \%$ \\
\hline
\end{tabular}

Na Tabela 7 pode-se observar que os 48 docentes que disseram ter em suas escolas de origem alunos com necessidades especiais informaram, por número de discentes, que os mesmos tinham deficiências dos seguintes tipos: 34 de ordem física, 28 auditiva, 25 visual, 19 mental e 1 outros tipos de deficiência. É bom dizer que, nessa questão, o participante pode assinalar mais de uma das alternativas.

Tabela 7 - Tipos de deficiências dos alunos das escolas de origem dos professores.

\begin{tabular}{lc}
\hline Tipos de deficiências & $\mathrm{n}$ \\
\hline Física & 34 \\
Mental & 19 \\
Auditiva & 28 \\
Visual & 25 \\
outras deficiências & 1 \\
\hline
\end{tabular}

Como se pode ver, na Tabela 8 , a maioria dos participantes, 42 deles, cerca de $62,7 \%$, responderam que não tinham conhecimentos suficientes para incluir um aluno deficiente em suas aulas de Educação Física; 25, por volta de 37,3\%, disseram ter.

Tabela 8 - Conhecimentos suficientes para incluir um aluno deficiente em suas aulas.

\begin{tabular}{lcc}
\hline conhecimento & $\mathrm{n}$ & $\%$ \\
\hline Tinham Conhecimentos & 25 & $37,3 \%$ \\
Não tinham conhecimentos & 42 & $62,7 \%$ \\
total & 67 & $100,0 \%$ \\
\hline
\end{tabular}


Na pergunta aberta 11- Em caso afirmativo, o que você prioriza em suas aulas para incluir esse aluno - , que deveria ser respondida apenas pelos informantes que responderam sim na pergunta fechada 10- que tinham conhecimentos suficientes para incluir um aluno deficiente em suas aulas - ; dos 25 informantes que responderam sim, 23 emitiram na questão 11 respostas vagas, do tipo: “... conscientização de todos os alunos"; “ ... preparo, estudo e naturalidade". Desses 25, apenas 2 apresentaram na questão 11 respostas mais fundamentadas, do tipo: “ ... em primeiro lugar não se deve rotular o aluno deficiente, voltar mais atenção a ele do que aos outros, deve-se tratá-lo de maneira natural e estimulá-lo, mostrando que ele é capaz de realizar as atividade"; " ... ter conhecimento das deficiências dos alunos que estão freqüentando as aulas, adequar metodologia de ensino que envolva todos os alunos e trabalho em equipe".

As respostas dadas pelos participantes às questões 10 e 11, leva-nos a constatar que, na realidade, 65 dos informantes, por volta de $97 \%$, não possuíam conhecimentos suficientes para incluir um aluno deficiente em suas aulas, em que pese que cerca de 37,3\% responderam que tinham conhecimentos.

Em relação à questão aberta 12- Em sua opinião, quais são os requisitos necessários para uma professor de Educação Física poder incluir um aluno Portador de Deficiência em suas aulas? - , 59 professores, cerca 88,1\% dos participantes, responderam a questão e 8 , por volta de $19,1 \%$, não responderam. Nas respostas emitidas pelos informantes houve várias colocações, dentre elas, pode-se destacar as seguintes: "necessidade de se ter cursos de capacitação para aquisição de conhecimentos sobre os vários tipos de deficiência e cursos de reciclagem sobre inclusão escolar" (colocações de 55 docentes); "estrutura adaptada do espaço físico" (colocação de 52 professores); "material didático adequado" (colocação de 51 participantes); "método adequado de ensino" (colocação de 50 professores); e "apoio técnico pedagógico especializado" (colocação de 49 informantes). Esses aspectos colocados pelos participantes estão dentro dos já levantados por vários autores, como por Martins (1996), Beraldo (1999), Luscher (1999) e Aguiar (2004).

Como se pode perceber, os participantes - ao responderem a questão 12 - apontam algumas das expectativas que são fundamentais para a implantação da educação inclusiva no ensino regular. Entre elas está a necessidade de cursos de reciclagem sobre educação inclusiva aos docentes, que na visão deste pesquisador devem ser ministrados não apenas por professores que tenham meramente domínio teórico sobre o assunto, não que se negue a importância do estudo e da reflexão dos teóricos, mas principalmente por aqueles que têm tido experiência de prática pedagógica com educação inclusiva, em âmbito escolar.

Na Tabela 9 vê-se que 65 dos professores que participaram da pesquisa, cerca de $97,0 \%$ dos assistentes técnicos pedagógicos, acreditavam que a participação do aluno portador de deficiência em aulas de educação física auxiliaria a inclusão do aluno na comunidade escolar. 
Tabela 9 - Acreditam que a participação do aluno portador de deficiência em aulas de educação física auxilia a inclusão do aluno na comunidade escolar.

\begin{tabular}{lcc}
\hline crença & $\mathrm{n}$ & $\%$ \\
\hline Acreditam & 65 & $97,0 \%$ \\
Não responderam & 02 & $3,0 \%$ \\
total & 67 & $100,0 \%$ \\
\hline
\end{tabular}

No que se refere à questão aberta 14- Em caso afirmativo, por quêe de que forma? -, que deveria ser respondida apenas pelos informantes que responderam sim na pergunta fechada 13 - Na sua opinião, a participação do aluno portador de deficiência em aulas de Educação Física auxilia a Inclusão do aluno na comunidade escolar? - , 55 informantes responderam a questão, por volta de $82,0 \%$ dos participantes, e 12 não responderam. Desses 55 professores, 53 emitiram respostas sem fundamentálas e apenas 2 as fundamentaram. As respostas emitidas por esses 2 docentes foram as seguintes: " ... porque no trabalho que executei com a participação ativa de alunos portadores de deficiências em minhas aulas, constatei que houve melhoria da socialização, diminuição de rejeição às diferenças, melhorou também a cooperação entre os alunos e nos intervalos das aulas percebi que os deficientes já não formavam grupos apenas entre eles, mas interagiam com os demais alunos da escola"; " ... porque a Educação Física é um agente educacional bom para realizar o processo de socialização e nesse sentido pode auxiliar na formação da cidadania, da solidariedade humana, pode melhorar a auto-estima e auxiliar na quebra de preconceitos, desenvolvendo o respeito as diversidades".

Os dizeres desses dois professores apontam que a participação de alunos com necessidades especiais em aulas de Educação Física, pode propiciar aos demais alunos o desenvolvimento de atitudes constantes do paradigma da Educação Inclusiva. Essas atitudes dizem respeito à manifestação de solidariedade, companheirismo, responsabilidade, cooperação e respeito ao outro, sem discriminação de características pessoais, físicas, sexuais ou sociais. Esses comportamentos atitudinais, indicadores de cidadania, estão expressos em objetivos dos Parâmetros Curriculares Nacionais de Educação Física para o Ensino Fundamental (BRASIL, Ministério da Educação e do Desporto, 1997), dos Parâmetros Curriculares Nacionais para o Ensino Fundamental (BRASIL, Ministério da Educação e do Desporto, 1998) e dos Parâmetros Curriculares Nacionais para o Ensino Médio (BRASIL, Ministério da Educação e do Desporto, 1999).

\section{CONSIDERAÇÕES FINAIS}

A Lei de Diretrizes e Bases da Educação Nacional (LDB) 9394/96, ao reconhecer a Educação Especial como modalidade de ensino que permeia todos os níveis escolares, deixa claro que não há, nos sistemas de ensino, tipos separados de educação. Sendo assim, a Educação Especial não é um subsistema e as unidades escolares devem ter um conjunto de recursos que devem ser organizados e 
disponibilizados para que todos os alunos possam desenvolver suas competências com respeito e dignidade, entre eles os que necessitam de apoios diferenciados. A escola precisa estar aberta para atender a todos e o governo deve oferecer reais condições para a implantação da escola inclusiva no país, fornecendo verbas, criando cursos de reciclagem para os docentes e atendendo as demais necessidades estruturais necessárias para tal ocorrência, como por exemplo, proporcionando apoio educacional especializado adequado para todos os alunos.

Como diz Mazzotta (1993), a implantação da educação inclusiva no ensino regular depende não só da boa vontade da sociedade civil, mas também da política de nossos governantes. E, na esfera política, tem-se visto, por várias vezes, que projetos são interrompidos, sem uma reflexão crítica sobre os mesmos, em decorrência das mudanças no governo. Não se pode esquecer que melhorar o nível de ensino é um esforço que, às vezes, demora décadas, requer treinamento contínuo de professores e o envolvimento das famílias e da comunidade, além da implementação das mudanças curriculares que devem ser feitas de forma processual, responsável e devem estar sempre muito bem fundamentadas.

Uma boa escola pública depende essencialmente de diretores e professores preparados, de um currículo conectado ao cotidiano, de instalações físicas razoáveis (como biblioteca, laboratórios e salas de aula que não estejam superlotadas), da vivência cultural dos estudantes e da participação da comunidade. Porém, tudo isso não se faz meramente com a boa vontade do povo, há necessidade de ações efetivas do governo, como destinação de verbas e melhor valorização do professor. O sucesso da inclusão de pessoas com necessidades especiais no ensino regular e de uma sociedade inclusiva depende da ação conjunta de toda população.

Fala-se muito em trabalhar a diversidade, mas, na prática, a comunidade e a escola ainda não dominam de modo eficaz o como realizar esse trabalho. Como já foi dito, a inclusão social e a inclusão de pessoas com necessidades especiais no ensino regular é um aprendizado e ocorrerá de forma lenta e gradual em nosso país. No âmbito escolar, os alunos "ditos normais" e seus pais têm apontado falhas na qualidade de ensino de nossas escolas de educação básica. Não é raro ouvir-se falar o quanto nossa educação é ruim e que não está preparada para ninguém. Esse é um dos desafios, espera-se que no futuro a escola inclusiva possa oferecer uma boa qualidade de ensino para todos e que não acabe sendo uma "utopia".

No que se refere especificamente à Educação Física, fundamentada na visão da cultura desportiva e competitiva, historicamente dominante nas propostas curriculares dessa área, apostar na educação que estimula a competitividade é deixar os alunos submetidos a um único estilo de viver. O mundo está competitivo? Certamente que sim! Entretanto isso não significa que todos devam viver de modo competitivo - tampouco que seja necessário encaminhar a educação dos alunos de modo a ensinar a competitividade. Se o mundo está assim, ele por si só já ensina isso aos mais novos. Cabe, então, às escolas, que têm como um de seus principais papéis o caráter formativo, apresentar aos alunos justamente o que o meio social 
atual não apresenta: a vida em cooperação e a possibilidade - rica, por sinal - de convivência com a diversidade. Os professores de Educação Física nas escolas podem contribuir para isso, mesmo na prática dos desportos escolares, onde essa ocorrência parece ser bem mais difícil, porém, possível. Basta, por exemplo, que todos os alunos participem de jogos e campeonatos. E quando digo todos, incluo os que não demonstram talento para nenhuma modalidade esportiva, os que têm dificuldades no controle do próprio corpo e mesmo os que, por características pessoais físicas, não seriam considerados aptos a praticar competitivamente esse ou aquele tipo de jogo. É uma questão de se adequar estratégias metodológicas.

As escolas terão de escolher o caminho a seguir, mas é bom lembrar que apostar na educação que ensina e estimula a competitividade é investir na permanência de uma característica de nosso mundo atual e deixar as pessoas sem outra opção, submetidos a estilo segregado de viver.

Costa e Bittar (2004) conceituam atividade física e/ou esportiva inclusiva como toda e qualquer atividade que, ao levar em consideração as potencialidades e as limitações físico-motoras, sensoriais e mentais dos seus praticantes, propicia aos mesmos efetiva participação nas diversas atividades físicas (como nas esportivas, recreativas, danças e ginásticas) e, conseqüentemente, possibilita o desenvolvimento de suas competências.

De Marco (1995) coloca: “Mais do que formar atletas, a educação física pode contribuir com o desenvolvimento pleno da pessoa, com a formação de uma consciência crítica, com o conceito de cidadania e com o próprio desenvolvimento da consciência corporal" (p. 33).

Refletindo sobre a formação do profissional em Educação Física, que culturalmente vem privilegiando o desenvolvimento de capacidades e habilidades físicas, que tem priorizado o desempenho físico, técnico e o corpo enquanto objeto de consumo, pode-se dizer que o papel do professor dessa área é acompanhar a evolução com uma postura ética diante das novas formas de consumo e com senso crítico, baseado no referencial científico e teórico-metodológico, não se comprometendo com a lógica do mercado. Isso significa dizer, que esse profissional deve vivenciar a cultura vigente com o discernimento de que na sociedade de consumo, classista e competitiva o ter ultrapassa o ser com valor ético; e deve ter identidade de educador e de agente transformador da sociedade. O modelo do corpo-instrumento, voltado para a produtividade, reflete-se na forma da sociedade capitalista tratar pessoas menos capazes, tidas como tais por supostamente não poderem participar de forma efetiva do processo de produção.

\section{REFERÊNCIAS}

AGUIAR, J. S. Educação Inclusiva: Jogos para o Ensino de Conceitos. $1^{\text {a }}$. ed. Campinas: Papirus Editora, 2004. 
AGUIAR, J. S. O Jogo no Ensino de Conceitos a Pessoas com Problemas de Aprendizagem: Uma Proposta Metodológica de Ensino. 2002. 71f. (Pesquisa de Pós-Doutorado em Educação Especial) - Programa de Pós-Graduação em Educação Especial da Universidade Federal de São Carlos, São Carlos.

ARANHA, M. S. F. Inclusão Social e Municipalização. In: MANZINI, E. J. Educação Especial: temas atuais. Unesp: Marília - Publicações, 2000.

BERALDO, P. B. As Percepções dos Professores de Escola Pública sobre a Inserção do Aluno tido como Deficiente Mental em Classes Regulares de Ensino. 1999. Dissertação de Mestrado. Centro de Educação e Ciências Humanas da Universidade Federal de São Carlos.

BRASIL, Ministério da Educação e do Desporto. Parâmetros Curriculares Nacionais - Ensino Fundamental - Educação Física. Brasília: Secretaria de Educação Fundamental, 1997.

BRASIL. Conselho Nacional de Educação/Câmera de Educação Básica. Resolução nº 2, 11 de setembro, 2001.

BRASIL. Lei de Diretrizes e Bases da Educação (Lei n. 9394, de 20 de dezembro de 1996). Diário Oficial da União, 23 de dezembro, 1996.

BRASIL. Parâmetros Curriculares Nacionais - Terceiro e Quarto Ciclos do Ensino Fundamental - (Introdução aos Parâmetros Curriculares Nacionais). Brasília: Secretaria de Educação Fundamental, 1998.

BRASIL. Presidente da República Federativa do Brasil. Constituição da República Federativa do Brasil. Diário Oficial da União n 191 - A, 5 de outubro, 1988.

BRASIL.. Parâmetros Curriculares Nacionais - Ensino Médio - Educação Física. Brasília: Secretaria de Educação Fundamental, 1999.

BUENO, S. T.; RESA, J. A. Z. Educación Física para niños y niñas com necessidades educativas especiales. Málaga: Ediciones Aljibe, 1995.

CARDOSO, C. S. Aspectos Históricos da Educação Especial: da exclusão a inclusão uma longa caminhada. Educação, n. 49, p. 137-144, 2003.

CARDOSO, M. C. F. Integração Educacional e Comunitária. Revista Brasileira de Educação Especial, 1, p. 89-100, 1992.

CARMO, A. A. Inclusão Escolar e a Educação Física: Que Movimentos são Estes? Integração, v. 14 - Edição Especial - Educação Física Adaptada -, p. 6-13, 2002.

CARVALHO, R. E. Temas em Educação Especial. Rio de Janeiro: WVA, 1998.

CIDADE, R. E.; FREITAS, P. S. Educação Física e Inclusão: Considerações para a Prática Pedagógica na Escola. Integração, v. 14 - Edição Especial - Educação Física Adaptada -, p. 27-30, 2002.

COSTA, A. M.; BITTAR, A. F. Metodologia aplicada ao deficiente físico. In Curso de Capacitação de Professores Multiplicadores em Educação Física Adaptada. Brasília: MEC; SEEP, 2004. p. 83-100.

DE MARCO, A. Educação Física ou Educação Motora? In: __. (Org.). Pensando a Educação Motora. Campinas: Papirus, 1995. p. 27-35.

DUARTE, E.; LIMA, S. M. T. Atividade Física para Pessoas com Necessidades Especiais: Experiências e Intervenções Pedagógicas. Rio de Janeiro: Editora Guanabara Koogan S. A., 2003.

ESTADO DE SÃO PAULO, Secretaria de Estado da Educação. Resolução no 11, de 18 de janeiro de 1980.

FÁVERO, E. A. G. PANTOJA, L. M. P.; MANTOAN, M. T. E. O Acesso de Alunos com Deficiência às Escolas e Classes Comuns da Rede Regular. Brasília: Procuradoria Federal dos Direitos do Cidadão, setembro de 2004.

JANNUZZI, G. S. M. Uma Luta Política. In Mesa-Redonda: Mudanças de Atitudes da Escola Frente à Integração. Vivência, 14, p. 14-15, 1993. 
LÜSCHER, A. Z. C. Educação Especial: Inclusão e Exclusão. Presença Pedagógica, v.28, n.5, p. 8184, 1999.

MACHADO, A. M., SOUZA, M. P. R.; SAYÃO, Y. As Classes Especiais e Uma Proposta de Avaliação Psicológica. In Conselho Regional de Psicologia de São Paulo (Ed.). p. 69-116. Educação Especial em Debate. São Paulo: Casa do Psicólogo, 1997.

MACHADO, N. A Educação Física e Recreação para o Pré-Escolar, Crianças de 0 a 6 anos. Brasília, 1985. MANTOAN, M. T. E. Integração X Inclusão - Educação para Todos. Pátio, n. 5, p. 49-51, 1998.

. A Integração de Pessoas com Deficiência. Contribuições para uma Reflexão sobre o Tema. São Paulo: Memnon, Edições Científicas, 1997.

. Compreendendo a Deficiência Mental, Novos Caminhos Educacionais. São Paulo: Editora Scipione Ltda, 1989.

. Uma Escola de Todos para Todos e com Todos: o mote da inclusão. Educação, n.49, p. 127-135, 2003.

. Caminhos Pedagógicos da Educação Inclusiva. In: GAIO, R.; MENEGHETTI, R.G.K. (Orgs.). Caminhos Pedagógicos da Educação Especial. (p. 79-94). Petrópolis: Editora Vozes, 2004.

MARTINS, L. A. R. Educação Integrada do Portador de Deficiência Mental: Alguns Pontos para Reflexão. Integração, 16, p. 27-32, 1996.

MAZZOTTA, M. J. S. Questão de Entendimento. In Mesa-Redonda: Mudanças de Atitudes da Escola Frente à Integração. Vivência, 14, p. 15-17, 1993.

MENDES, E. G. Educação Inclusiva: Realidade ou Utopia? Apostila produzida para a Mesa-Redonda do LIDE-USP / São Paulo, 1999.

. História da Educação Especial no Brasil. Apostila produzida para uso interno da disciplina "Educação Especial no Brasil", do PPG - EES da UFSCar. São Carlos/SP, 2000.

MINISTÉRIO DA SAÚDE, Conselho Nacional de Saúde. Resolução no 196/96, Sobre Pesquisa Envolvendo Seres Humanos. Brasília, 1996.

MRECH, L. M. Educação Inclusiva: Realidade ou Utopia? Apostila produzida para a Mesa-Redonda do LIDE-USP / São Paulo, 1999.

OLIVEIRA, A. A. S.; POKER, R. B. Educação inclusiva e municipalização: a experiência em educação especial de Paraguaçu Paulista. Revista Brasileira de Educação Especial, Marília, v. 8, n. 2, p. 233-244, 2002.

SASSAKI, R. D. Inclusão - Construindo uma Sociedade para Todos. 3. ed. Rio de Janeiro: WVA, 1999. . Inclusão - Construindo uma Sociedade para Todos. Rio de Janeiro: WVA, 1997.

SILVA, S. B. Análise das relações existentes na legislação que orienta a formação profissional dos especialistas em Educação Física e Desportos e os planos nas áreas educacional e desportiva no Brasil. 1993. (Dissertação de Mestrado) - Escola de Educação Física, Universidade de São Paulo, São Paulo.

SOUZA, W. C. A Inclusão do Educando com Deficiência na Escola Pública Municipal de Goiânia: O Discurso de Professores de Educação Física. 2003. (Dissertação de Mestrado) - Faculdade de Educação Física, Universidade Estadual de Campinas.

STAINBACK, S.; STAINBACK, W. Inclusão - Um Guia para Educadores. Porto Alegre: Artmed Editora, 1999.

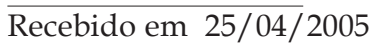

Reformulado em 06/07/2005

Aprovado em 30/08/2005 